\title{
RESENHA DE "UM APÓLOGO" DE MACHADO DE ASSIS EM SEIS VOZES, ORGANIZADO POR ÂNGELA VAZ LEÃO
}

\author{
Review of "Um apólogo" de Machado de Assis em seis vozes, \\ organized by Ângela Vaz Leão
}

\section{LEÃo, Ângela Vaz (Org.). "Um apólogo" de Machado de Assis em seis vozes. Belo Horizonte: Ed. PUC Minas, 2015.}

\section{Walter Carlos Costa}

Universidade Federal de Santa Catarina/Universidade Federal do Ceará/CNPq Florianópolis, Santa Catarina/Fortaleza, Ceará, Brasil

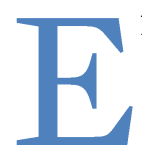

xiste certo consenso de que a literatura brasileira carece de divulgação adequada no exterior, se comparada com outros produtos da cultura do país como o futebol, a publicidade, a moda, a telenovela e a música popular. Isso é particularmente verdadeiro no hemisfério norte, mesmo para autores cultuados pelos especialistas brasileiros e estrangeiros, como Machado de Assis. Embora haja exceções notáveis, como a Holanda, graças ao trabalho do tradutor, crítico e memorialista August Willemsen, as traduções publicadas na Europa Ocidental e nos Estados Unidos costumam ser poucas e nem sempre representativas do corpus machadiano. Coleções prestigiosas como a Bibliothèque de la Pléiade, da Gallimard, na França, ou a Meridiani, da Mondadori, na Itália, ainda não contêm obras brasileiras. Várias iniciativas têm sido tomadas para contornar essa situação, entre elas edições com participação de brasileiros, como a Machado de Assis Anthology, organizada por Ian Alexander e Rosalia Neumann Garcia, publicada como e-book Kindle pela Amazon.com (sem data), ou por brasileiros bilíngues como Un capitaine de volontaires, traduzida por Dorothée de Bruchard e publicada pelas editoras alternativas La Découvrance \& Les Arêtes (2015).

"Um apólogo" de Machado de Assis em seis vozes se inscreve nessa corrente. Trata-se de um empreendimento universitário e memorialístico, de estudos literários e de estudos linguísticos. Faz parte também de projetos que reúnem um pequeno texto traduzido a várias línguas, como Poema de sete 
faces, de Carlos Drummond de Andrade (Companhia das Letras, 2011), que foi objeto do minucioso estudo de Berthold Zilly "Uma antologia sui generis: Sete faces do 'Poema de sete faces', de Carlos Drummond de Andrade" (in: MarieHélène Catherine Torres; Luana Ferreira de Freitas; Walter Carlos Costa, orgs. Literatura traduzida: Antologias, coletâneas e coleções. Fortaleza: Substânsia, 2016, pp. 155-231). É, ainda, um livro bastante pessoal, em que Ângela Vaz Leão reúne colegas, amigos e um familiar, um pouco como costumam fazer, de modo frutífero, os músicos populares brasileiros.

O livro, publicado pela Editora PUC Minas, revela a força do sistema universitário brasileiro. Contrariamente ao que acontece em países como a França, os Estados Unidos, a Alemanha e a Inglaterra, onde a cultura letrada é discutida em suplementos dos jornais, no rádio e na televisão, no Brasil a discussão de temas literários está praticamente restrita às publicações acadêmicas.

A dedicatória já diz muito sobre o projeto: os homenageados são, de um lado, o professor e crítico Wilton Cardoso, que formou gerações de professores e pesquisadores na área de Letras da UFMG, e, de outro, uma das colaboradoras do livro, amiga e ex-aluna, falecida antes de sua publicação, e o neto da organizadora, seu secretário e interlocutor. Como em outros momentos do livro, as gerações se cruzam e se alimentam.

No prólogo, Ângela conta como surgiu a ideia do livro. Lembra que tudo começou quando foi fazer uma de suas faxinas periódicas. Ao descartar papéis, descobriu uma antiga tradução sua, "L'aiguille et le fil", seguindo "A agulha e a linha", título da primeira publicação do texto na Gazeta de Notícias, em 1885, e que Machado renomeou "Um apólogo" quando o incluiu em Várias histórias, em 1896. Este e vários outros contos do volume foram utilizados nas aulas de tradução francesa cursadas pela organizadora. Devemos, portanto, o presente livro ao fato de que o ensino de francês como língua estrangeira incluía exercícios avançados de versão literária.

As outras evocações de Ângela reconstituem um Brasil mais culto que o atual, em que uma jovem se encantava com textos literários, contados pelo pai ou lidos na biblioteca da escola ou da igreja. Entre os textos recordados estão autores como Jules Verne, e também antologias e coletâneas que muitos intelectuais recordam como importantes em sua formação, como o Tesouro da juventude.

Lamentando o persistente pouco conhecimento da obra de Machado no exterior, Ângela planejou o livro com seis traduções de "Um apólogo": para o francês, o espanhol, o italiano, o romeno, o alemão e o inglês. Assim, abarcou 
as principais línguas românicas e duas germânicas, embora, como ela mesma observa, o romeno seja mais latino por sua estrutura que por seu léxico. $O$ mesmo caberia dizer do inglês, cujo léxico se latinizou muito ao longo dos séculos.

Todas as tradutoras, com exceção da tradutora para o romeno, são brasileiras traduzindo um conto brasileiro para uma língua estrangeira. A tranquilidade com que Ângela detalha todo o processo indica bem a segurança linguística dessa geração com sólida formação filológica, abarcando língua e cultura, para a qual traduzir para uma língua estrangeira parece natural.

Ainda no prólogo, Ângela apresenta cada uma das tradutoras, justificando e louvando sua competência. Na formação das tradutoras brasileiras, chama a atenção, além da UFMG e da PUC Minas, a Aliança Francesa, o Instituto Goethe e o Instituto Brasileiro-Uruguaio de Cultura. A todas as tradutoras Ângela pediu um comentário livre. Com isso, pretendia "fazer do livro um possível material didático, utilizável em cursos de línguas estrangeiras" (p. 17), o que mostra uma preocupação teórica, crítica e também muito prática. As circunstâncias do texto se misturam com as circunstâncias da vida, e o relato de umas e outras dá uma dimensão biográfica e autobiográfica ao livro, que fica sendo, também, a história de um grupo de filólogas de Belo Horizonte, apaixonadas por línguas e literaturas e unidas por grande amizade.

A tradução para o inglês conta com duas tradutoras porque a tradutora inicial, Astrid Masetti Lobo Costa, faleceu depois de terminar a tradução, que foi revista por Suely Maria de Paula e Silva Lobo. Por outro lado, a tradutora para o espanhol, Melânia Silva Aguiar, ex-professora de Literatura Brasileira na UFMG, ex-diretora do Instituto de Cultura Uruguaio-Brasileiro em Montevidéu e professora na Pós-graduação em Letras da PUC Minas, é também a autora da introdução, "Entre o contingente e o universal", título que vale por uma síntese da estética de Machado de Assis. Melânia, que faleceu recentemente, situa o texto no conjunto da obra de Machado de Assis e destaca seus principais aspectos temáticos e procedimentos narrativos. Destaca as palavras "mucama" e "imperador", observando que elas, como outras, sugerem que "o fundo social está presente", embora o texto trate "de aspectos da psicologia humana". Melânia assinala ainda como um desafio para o tradutor a presença em "Um apólogo" tanto de arcaísmos como de vocábulos típicos da realidade brasileira da época.

À introdução seguem-se o texto original de "Um apólogo" e as seis traduções, cada uma precedida de uma pequena apresentação. Cabe lembrar 
que "Um apólogo" é um dos textos preferidos dos antologistas escolares brasileiros, talvez por apresentar um Machado de Assis mais abordável, com uma "mensagem" mais clara e uma narrativa mais direta e menos ambígua. $\mathrm{O}$ próprio Machado pode ter sentido essa "facilidade" do texto, expressa no título "A agulha e a linha", e que, mudado para "Um apólogo", ganha um ar mais intelectualizado.

Em seu comentário, "A tradução dos pronomes de tratamento para o espanhol da América: explicação necessária", Melânia examina a questão dos pronomes de tratamento. Ela optou por usar a forma vos no final do conto, para denotar "o grau de informalidade do alfinete para com a agulha", o que cumpre, em sua opinião, dois objetivos: "manter três diferentes formas de pronomes de tratamento" e contribuir para a difusão de uma variante hispanoamericana.

A tradução para o francês, de autoria da organizadora do volume, é mais ortodoxa em suas opções tradutórias, tanto na voz do narrador como nas vozes dos personagens. Não por acaso, talvez, Ângela Vaz Leão prefere discutir a "estruturação discursiva" do conto, "que o aproxima de uma peça de teatro". Enfatiza também o componente "moralista" (no sentido dos "moralistas" franceses como La Rochefoucauld e Vauvenargues) do Machado escritor, componente, podemos dizer, que perpassa toda sua obra.

A tradução para o italiano é de autoria de Lúcia Fulgêncio, professora de Língua Italiana e de Linguística da UFMG. Como Melânia, Lúcia se interessa pela oscilação no pronome de tratamento usado pela linha em relação à agulha, primeiro um distante "a senhora" e, depois, no calor da luta, "você"; suas opções são, respectivamente "Lei" e "tu" e "voi". Lúcia justifica sua escolha pelo fato de "voi como tratamento singular, usado abundantemente na língua e na literatura italiana do século XIX, por exemplo por Manzoni no seu livro I Promessi Sposi, para indicar a segunda pessoa singular do discurso", o que daria "ao texto traduzido um caráter de época", embora reconheça que "o pronome voi italiano carrega um tom de formalidade não presente no uso do tu em português". A tradutora explica que, ainda se inspirando em Manzoni, usa o expediente da apócope de formas como quel para sugerir um arcaísmo que identifica no léxico machadiano.

Em "O bem coser do texto", Suely de Paula e Silva Lobo comenta a tradução que revisou e coassina com Astrid Masetti Lobo Costa. Suely não trata de problemas tradutórios; prefere se concentrar no exame do jogo de metáforas do texto como tecido. 
Comentando sua tradução, Tarcísia Lobo Ribeiro examina o gerúndio, que considera uma das dificuldades da tradução do português para o alemão. Conclui que é impossível "verter o gerúndio empregado em português por um elemento verbal da mesma classe no alemão", e usa "elementos gramaticais ou lexicais", para contornar o problema.

Finalmente, Micaela Ghitescu, a única estrangeira das tradutoras, centra seu comentário na questão do gênero das palavras, questão evocada, aliás, no célebre ensaio "Aspectos linguísticos da tradução", de Roman Jakobson. Micaela nota que agulha (acul) é do gênero masculino, mas linha (ața), do gênero feminino, e conclui:

no "Apólogo" em romeno, o diálogo entre acul e ața é um confronto entre os dois sexos, o que - diríamos nós - não deixa de acrescentar um matiz psicológico ao texto machadiano: se bem que cada um dos dois protagonistas demonstre menosprezo para com o trabalho do outro, acul tem uma atitude bastante "machista" enquanto ața, ainda que chamada de "orgulhosa", prefere em dado momento encerrar a discussão, calar-se e... ir andando. (p. 72)

Concluindo, podemos dizer que "Um apólogo" de Machado de Assis em seis vozes constitui uma contribuição para a crescente mundialização de Machado de Assis, dentro de um enfoque sui generis, reunindo virtudes filológicas raras nos dias que correm e tratando aspectos temáticos, narratológicos e tradutológicos, mesmo que a disciplina dos estudos da tradução não seja mencionada.

WALTER CARLOS COSTA é professor do Departamento de Língua e Literatura estrangeiras da Universidade Federal de Santa Catarina, pesquisando literatura hispano-americana (sobretudo a obra de Jorge Luis Borges), Literatura Comparada, Estudos da Tradução (especialmente a conexão entre literatura traduzida e literatura nacional) e Literatura Fantástica Francesa. Foi presidente da ABRAPT (Associação Brasileira de Pesquisadores em Tradução na gestão 2010-2013). Atualmente está em colaboração técnica no Departamento de Letras Estrangeiras da Universidade Federal do Ceará. E-mail: walter.costa@gmail.com 